\title{
Lyophilized Cell-Free Supernatants of Lactobacillus Isolates Exhibited Antibiofilm, Antioxidant, and Reduces Nitric Oxide Activity in Lipopolysaccharide-stimulated RAW 264.7 cells
}

\author{
Phoomjai Sornsenee ${ }^{1}$, Moragot Chatatikun ${ }^{2,3,4}$, Watcharapong Mitsuwan ${ }^{5,6,7}$, Kantapich Kongpol ${ }^{2,4}$, Nateelak \\ Kooltheat $^{2,4}$, Sasirat Sohbenalee ${ }^{2}$, Supawita Pruksaphanrat ${ }^{2}$, Amron Mudpan ${ }^{2}$, Chonticha Romyasamit ${ }^{\text {Corresp. } 2,3,5}$ \\ ${ }^{1}$ Department of Family and Preventive Medicine, Faculty of Medicine, Prince of Songkla University, Hat Yai, Songkhla, Thailand \\ 2 Department of Medical Technology, School of Allied Health Sciences, Walailak University, Thasala, Nakhon Si Thammarat, Thailand \\ ${ }^{3}$ Center of Excellence Research for Meliodosis (CERM), Walailak University, Thasala, Nakhon Si Thammarat, Thailand \\ 4 Research Excellence Center for Innovation and Health Product, Walailak University, Thasala, Nakhon Si Thammarat, Thailand \\ 5 Research Center of Excellence in Innovation of Essential Oil, Walailak University, Thasala, Nakhon Si Thammarat, Thailand \\ 6 One Health Research Center, Walailak University, Thasala, Nakhon Si Thammarat, Thailand \\ 7 Akkhraratchakumari Veterinary College, Walailak University, Thasala, Nakhon Si Thammarat, Thailand \\ Corresponding Author: Chonticha Romyasamit \\ Email address: chonticha.ro@wu.ac.th
}

Background. Probiotics can release bioactive substances known as postbiotics, which can inhibit pathogenic microorganisms, improve immunomodulation, reduce antioxidant production, and modulate the gut microbiota. Methods. In this study, we evaluated the in vitro antimicrobial effects, antioxidant activity, and anti-inflammatory potential of 10 lyophilized cell-free supernatants (LCFS) of Lactobacillus isolates. LCFS was obtained via centrifugation and subsequent lyophilization of the supernatant collected from the culture medium ofeach isolate. The antibacterial and antibiofilm activities of the LCFS were determined using broth microdilution. The antioxidant potential was evaluated by measuring the total phenolic and flavonoid contents and 2,2-Diphennyl-1-picrylhydrazyl (DPPH) and 2,2'-azinobis(3-ethylbenzothiazoline-6-sulfonic acid) radical cation ( $\mathrm{ABTS}^{+}$) radical scavenging activities. Results. All the isolates were able to inhibit the four tested pathogens. The isolates exhibited strong antibiofilm activity and eradicated the biofilms formed by Acinetobacter buamannii and Escherichia coli . All the prepared Lactobacillus LCFS contained phenols and flavonoids and exhibited antioxidant activities in the DPPH and $\mathrm{ABTS}^{+}$radical scavenging assays. The MTT (3-[4,5-dimethylthiazol-2-yl]-2,5 diphenyl tetrazolium bromide) assay revealed that LCFS was not cytotoxic to RAW 264.7 cells. In addition, the ten Lactobacillus LCFS decreased the production of nitric oxide.

Conclusions. All the isolates have beneficial properties. This research sheds light on the role of postbiotics in functional fermented foods and pharmaceutical products. Further 
research to elucidate the precise molecular mechanisms of action of probiotics is warranted. 
1 Lyophilized Cell-Free Supernatants of Lactobacillus Isolates Exhibited Antibiofilm, 2 Antioxidant, and Reduces Nitric Oxide Activity in Lipopolysaccharide-stimulated RAW

$3 \quad 264.7$ cells

4

5

6 Phoomjai Sornsenee ${ }^{1}$, Moragot Chatatikun ${ }^{2,3,4}$, Watcharapong Mitsuwan ${ }^{5,6,7}$, Kantapich

7 Kongpol $^{2,3}$, Nateelak Kooltheat ${ }^{2,3}$, Sasirat Sohbenalee ${ }^{2}$, Supawita Pruksaphanrat ${ }^{2}$, Amron

8 Mudpan $^{2}$, Chonticha Romyasamit $2,4,6^{*}$

9

10

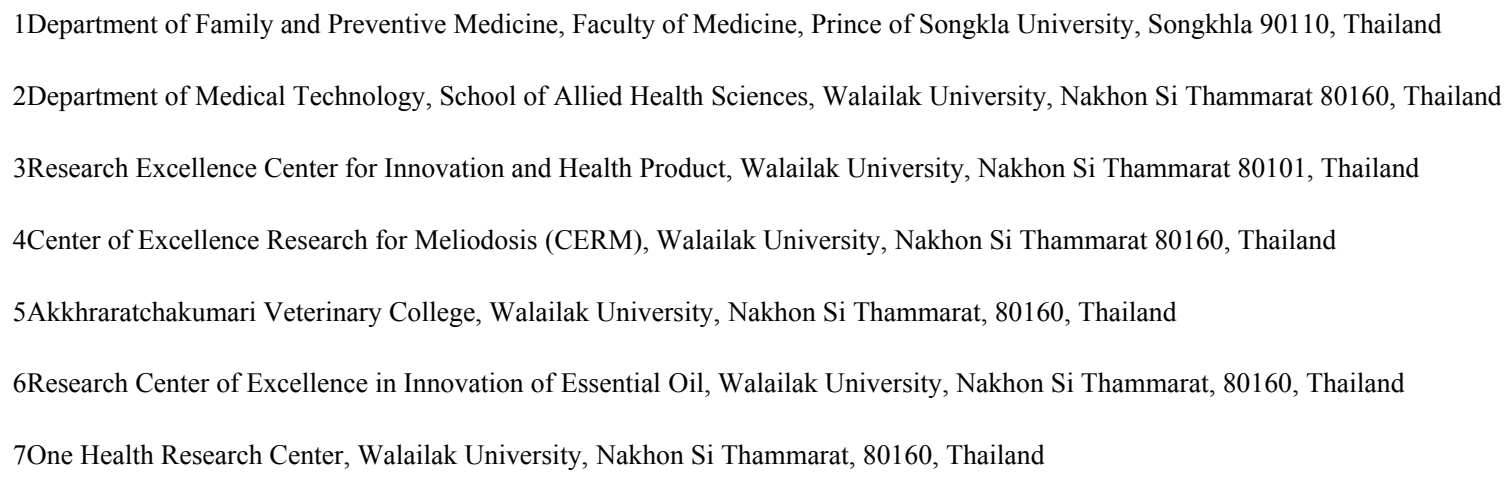

Corresponding Author:

Chonticha Romyasamit ${ }^{2,4,6}$

Department of Medical Technology, School of Allied Health Sciences, Walailak University, Nakhon Si Thammarat 80160, Thailand

Email address: chonticha.ro@wu.ac.th

\section{Abstract}

Background. Probiotics can release bioactive substances known as postbiotics, which can inhibit pathogenic microorganisms, improve immunomodulation, reduce antioxidant production, and modulate the gut microbiota.

Methods. In this study, we evaluated the in vitro antimicrobial effects, antioxidant activity, and anti-inflammatory potential of 10 lyophilized cell-free supernatants (LCFS) of Lactobacillus isolates. LCFS was obtained via centrifugation and subsequent lyophilization of the supernatant collected from the culture medium of each isolate. The antibacterial and antibiofilm activities of 
32 the LCFS were determined using broth microdilution. The antioxidant potential was evaluated by

33 measuring the total phenolic and flavonoid contents and 2,2-Diphennyl-1-picrylhydrazyl (DPPH)

34

35

36

37

38

39

40

41

42

43

44

45

46

47

48

49

50

51

52

53

54

55

56

57

58

59

60

61 and 2,2'-azinobis(3-ethylbenzothiazoline-6-sulfonic acid) radical cation $\left(\mathrm{ABTS}^{+}\right.$) radical scavenging activities.

Results. All the isolates were able to inhibit the four tested pathogens. The isolates exhibited strong antibiofilm activity and eradicated the biofilms formed by Acinetobacter buamannii and Escherichia coli. All the prepared Lactobacillus LCFS contained phenols and flavonoids and exhibited antioxidant activities in the DPPH and $\mathrm{ABTS}^{+}$radical scavenging assays. The MTT (3-[4,5-dimethylthiazol-2-yl]-2,5 diphenyl tetrazolium bromide) assay revealed that LCFS was not cytotoxic to RAW 264.7 cells. In addition, the ten Lactobacillus LCFS decreased the production of nitric oxide.

Conclusions. All the isolates have beneficial properties. This research sheds light on the role of postbiotics in functional fermented foods and pharmaceutical products. Further research to elucidate the precise molecular mechanisms of action of probiotics is warranted.

\section{Introduction}

The term "probiotics" refers to living or dead microorganisms that confer health benefits to a host when administered in adequate amounts (Hotel \& Cordoba, 2001). Probiotic microorganisms exert their benefits through two mechanisms: direct effects on living cells and indirect effects involving the production of several metabolites (Vinderola, Matar, Palacios, \& Perdigón, 2007). The most frequently used probiotic microorganisms are lactic acid bacteria (LAB) such as Lactobacillus spp., Lactococcus spp., Carnobacterium spp., Enterococcus spp., Streptococcus spp., Pediococcus spp., and Propionibacterium spp.(Pinto, Barbosa, Albano, - - Isidro, \& Teixeira, 2020; Sornsenee, Singkhamanan, Sangkhathat, Saengsuwan, \& Romyasamit, 2021). Generally, Lactobacillus spp. are the most popular probiotic microbes owing to their "Generally

Recognized As Safe (GRAS)" status and their regulation by the US Food and Drug Administration (FDA) for human and animal consumption (FAO/WHO, 2002; Sornsenee et al., 2021). For example, L. acidophilus CL1285, L. casei LBC80R, L. rhamnosus CLR2 (Bio-K Plus International Inc, Laval, Quebec, Canada), L. acidophilus (La-5®), and Bifidobacterium lactis

PeerJ reviewing PDF | (2021:09:65883:1:1:NEW 20 Oct 2021) 
62 (BB-12®) (Pharma Nord, Nederland), have been used as probiotics in pharmaceutical and diet 63 supplements (Organization, 2002).

64 The beneficial effects of Lactobacillus as probiotics are not limited to the health of the 65 gastrointestinal tract (GIT) and extend to conditions such as diabetes, obesity, hyperlipidemia, 66 cancer, dementia, Crohn's disease, and constipation (Plaza-Diaz, Ruiz-Ojeda, Gil-Campos, \& 67 Gil, 2019). Probiotics produce organic acids (acetic acid, propionic acid, and lactic acid), 68 aromatic compounds, diacetyl, hydrogen peroxide, antimicrobial substances, bacteriocins, and 69 other unknown metabolites (Barzegari et al., 2020; Bermudez-Brito, Plaza-Diaz, Munoz70 Quezada, Gomez-Llorente, \& Gil, 2012; Cremon, Barbaro, Ventura, \& Barbara, 2018) that can 71 inhibit several pathogens such as Clostridium difficile (Shahrokhi \& Nagalli, 2020), Vibrio 72 parahaemolyticus (Behera, Ray, \& Zdolec, 2018), carbapenem-resistant Escherichia coli (Chen 73 et al., 2019), Klebsiella pneumoniae (Chen et al., 2019), Listeria monocytogenes (Kariyawasam, 74 Yang, Lee, \& Paik, 2020), Staphylococcus aureus (Melo et al., 2016), Salmonella enteritidis 75 (Sornsenee et al., 2021), and Helicobacter pylori (Ji \& Yang, 2021). Probiotics can lower 76 cholesterol levels, boost the immune system, promote the secretion of immunoglobulin IgA, 77 serve as antioxidants, exhibit antidiabetic properties, and suppress inflammation (AlKalbani, 78 Turner, \& Ayyash, 2019; De Marco et al., 2018; Singhal, Maurya, Mohanty, Kumar, \& Virdi, 2019; Xu, Qiao, Peng, Shi, \& Dia, 2021). Several studies have shown that Lactobacillus can inhibit biofilm formation by many pathogens (Carvalho, Teixeira-Santos, Mergulhão, \& Gomes, 2021; Gómez, Ramiro, Quecan, \& de Melo Franco, 2016; Ji \& Yang, 2021; Shaaban, Abd ElRahman, Al-Qaidi, \& Ashour, 2020). Other reports have shown that metabolites produced by probiotics have antivirulence activity (Stefania et al., 2017).

Members of the genus Lactobacillus are gram-positive bacteria, aerotolerant anaerobes or microaerophilic, rod-shaped, and non-spore-forming, with low DNA G+C content (Klaenhammer, Barrangou, Buck, Azcarate-Peril, \& Altermann, 2005)]. This genus comprises 261 species as of March 2020, with extreme diversity at phenotypic, ecological, and genotypic levels (Zheng et al., 2020). We previously identified 10 Lactobacillus isolates from fermented palm sap collected from a local market in the Songkhla Province of Southern Thailand. All Lactobacillus isolates met the established criteria to qualify as potential probiotics, including resistance to gastrointestinal conditions, adherence to human intestinal cells, and susceptibility to transmissible antibiotics. These isolates possessed antimicrobial activity against a wide range of 
93 pathogens (Sornsenee et al., 2021). From these data, 10 Lactobacillus isolates are promising 94 potential candidates for use as probiotic applications as functional foods and pharmaceutical 95 products. However, we still lack information about the antibiofilm, antioxidant, and antiinflammatory activities of Lactobacillus isolates. Thus, the present work aimed (i) to evaluate the antibacterial and antibiofilm activities of lyophilized cell-free supernatants (LCFS) of Lactobacillus against pathogens, (ii) to evaluate the total phenolic and flavonoid contents and free-radical-scavenging activities, and (iii) to evaluate the toxicity of the cell-free supernatants (CFS) and their anti-inflammatory activity using RAW 264.7 cells.

\section{Materials \& Methods}

\subsection{Microorganisms and culture conditions}

Ten Lactobacillus isolates, including L. paracasei (T0601, T0602, T0603, T0901, T0902, T1301, T1304, and T1901), L. fermentum (T0701), and L. brevis (T0802), were isolated from fermented palm sap collected from a local market in the Songkhla Province of Southern Thailand and characterized as potential probiotics in our previous study. These isolates were used in the present study (Sornsenee et al., 2021). First, they were grown in de Man, Rogosa and Sharpe (MRS) broth (HiMedia, Mumbai, India) at $37^{\circ} \mathrm{C}$ for overnight. After that, all isolates were stored at $-80^{\circ} \mathrm{C}$ in $30 \%(\mathrm{v} / \mathrm{v})$ glycerol (Sigma, Steinheim, Germany).

Three reference strains, E. coli DMST4212, A. baumannii DMST 2271, and S. aureus DMST 2928, obtained from the Department of Medical Sciences Thailand (DMST), were used in this study. One clinical isolate, methicillin-resistant $S$. aureus (MRSA), was identified using matrixassisted laser desorption ionization time-of-flight mass spectrometry/MS mass spectrometry. These strains were cultured on trypticase soy (TSA) agar (HiMedia, Mumbai, India), and the agar plates were incubated at $37^{\circ} \mathrm{C}$ for $18 \mathrm{~h}$ under aerobic conditions. The colonies were transferred to trypticase soy broth (HiMedia, Mumbai, India) and incubated at $37^{\circ} \mathrm{C}$ for $18 \mathrm{~h}$. Each strain was stored at $-80^{\circ} \mathrm{C}$ in brain heart infusion broth with $30 \%$ glycerol until further use.

\subsection{Preparation of CFS}

CFS were prepared according to Melo TA, et al. (Melo et al., 2016) with slight modifications. Briefly, each Lactobacillus isolate was cultured in $100 \mathrm{~mL}$ of MRS broth and incubated at $37^{\circ} \mathrm{C}$ for $18 \mathrm{~h}$ under anaerobic conditions. The supernatant was obtained by centrifugation $(\times 6000 \mathrm{~g}$, 
$12410 \mathrm{~min}, 4^{\circ} \mathrm{C}$ ). The centrifuged supernatant was passed through a sterile $0.22 \mu \mathrm{m}$-pore-size filter

125 unit (Sigma, Steinheim, Germany). The filtrate was collected for freeze-drying.

126

127

\subsection{Lyophilization}

128 CFS of each Lactobacillus isolate and MRS medium without Lactobacillus (MRS control) were 129 frozen at $-80^{\circ} \mathrm{C}$ for $24 \mathrm{~h}$. The samples were lyophilized (Lyophilization Systems, Inc, USA)

130

131

132

133

134 135

136

137

138

139

140

141

142

143

144

145

146

147

148

149

150

151

152

153

154

from $-40^{\circ} \mathrm{C}$ to $-30^{\circ} \mathrm{C}, 0.2 \mathrm{mbar}$. The entire freeze-drying process was performed in $24 \mathrm{~h}$, and the freeze-dried powders were stored at $-20^{\circ} \mathrm{C}$. They were then rehydrated with sterile deionized water prior to use.

\subsection{Determination of minimum inhibitory concentration (MIC) and minimal bactericidal} concentration $(M B C)$

The antibacterial activities of each LCFS against the four pathogenic bacteria were assessed using the method of microdilution in 96-well plates according to the Clinical and Laboratory Standards Institute (CLSI) 2021 guidelines ((CLSI), 2021). Serial dilution was performed starting with $100 \mathrm{mg} / \mathrm{mL}$ of lyophilized CFS of Lactobacillus in Mueller Hinton broth (MHB) (HiMedia, Mumbai, India). The bacterial suspension $\left(5 \times 10^{5} \mathrm{CFU} / \mathrm{mL}\right)$ was inoculated into each well, and the plates were incubated at $37^{\circ} \mathrm{C}$ for $18 \mathrm{~h}$. Then, resazurin (Sigma, Steinheim, Germany) was used to determine the MIC values. The MIC was defined as the lowest concentration that completely inhibited the bacterial growth, which presented as a blue color (Hussain et al., 2011). The MBC was determined using the extract that yielded significant MIC values by dropping the culture onto TSA plates. The entire experiment was performed three times with three independent repetitions.

\subsection{Biofilm inhibition assay}

The effects of LCFS of Lactobacillus on biofilm formation of E. coli DMST4212 and A. baumannii DMST 2271 were performed following a method that was modified from published by Yang et al. (Yang et al., 2021). Briefly, overnight cultures of E. coli DMST4212 and $A$. baumannii DMST 2271 were suspended in MHB to a cell density of $5 \times 10^{5} \mathrm{CFU} / \mathrm{mL}$ and then inoculated into 96-well plates supplemented with $1 \times$ MIC and $2 \times$ MIC of CFS of Lactobacillus. The plates were incubated at $37^{\circ} \mathrm{C}$ for $24 \mathrm{~h}$ under aerobic conditions. Then, the medium was 
155 removed, the biofilms were washed with phosphate-buffered saline (PBS) (pH 7.4) three times, 156 and fixed with $99 \%(\mathrm{v} / \mathrm{v})$ methanol $(200 \mu \mathrm{L})$ for $15 \mathrm{~min}$. The biofilm was stained with $0.1 \%$ $157(\mathrm{w} / \mathrm{v})$ crystal violet solution $(200 \mu \mathrm{L})$ for $10 \mathrm{~min}$. The wells were rinsed four times with distilled 158 water to remove excess dye. The biofilms were dissolved in 95\% (v/v) ethanol and absorbance 159 was measured at an optical density (OD) of $570 \mathrm{~nm}$. Each test was performed in triplicate. The 160 percentage of biofilm inhibition was calculated using the following equation:

161 162 163 164 165 166 167 168 169

170

171

172

173

174 175

Biofilm inhibition $(\%)=[(\mathrm{OD} 570$ of control well - OD 570 of treated well) $/$ OD 570 of control well] $\times 100$.

\subsection{Biofilm eradication assays}

The effects of LCFS of Lactobacillus on the eradication of biofilms produced by E. coli DMST4212 and A. baumannii DMST 2271 were tested according to reported procedures of Perumal et al. (Perumal \& Mahmud, 2013) with slight modifications. Briefly, an overnight culture of each E. coli DMST4212 and A. baumannii DMST 2271 was added to a 96-well microtiter plate and incubated at $37^{\circ} \mathrm{C}$ for two days to allow the development of a biofilm. Then, the wells were rinsed with PBS ( $\mathrm{pH} 7.4$ ) to remove non-adherent cells. The biofilms established for two days in each well were subsequently treated with $1 \times$ MIC and $2 \times$ MIC of CFS of Lactobacillus and incubated at $37^{\circ} \mathrm{C}$ for $24 \mathrm{~h}$. After incubation, the plates were removed, gently washed with PBS three times, and stained with $0.1 \%$ (w/v) crystal violet solution, as described previously, to determine the extent of biofilm inhibition. Each test was performed in triplicate. The percentage of biofilm eradication was calculated using the following equation:

Biofilm eradication $(\%)=[($ OD 570 of control well - OD 570 of treated well) $/$ OD 570 of control well] $\times 100$.

\subsection{Determination of antioxidant activity}

2.7.1 Total phenolic content (TPC) assay

The Folin-Ciocalteu method was used to determine TPC, as described by Chatatikun et al. (Chatatikun et al., 2020)] with some modifications. Briefly, LCFS of Lactobacillus was diluted in distilled water to a concentration of $50 \mathrm{mg} / \mathrm{mL}$. Subsequently, $100 \mu \mathrm{L}$ of $0.1 \mathrm{M} \mathrm{Na}_{2} \mathrm{CO}_{3}$ solution and $100 \mu \mathrm{L}$ of 10\% Folin-Ciocalteu reagent (Sigma-Aldrich, St. Louis, USA) were mixed in a well of a 96-well plate and incubated for $1 \mathrm{~h}$. The absorbance was measured at 750 
186 nm. A standard curve was plotted using gallic acid with a concentration range of 1.569-200

$187 \mu \mathrm{g} / \mathrm{mL}$. TPC was determined as gallic acid equivalents (GAE) in $\mathrm{mg} / \mathrm{g}$ of lyophilized CFS of

188 Lactobacillus.

189 2.7.2 Total flavonoid content (TFC) assay

190 The TFC of the LCFS of Lactobacillus was determined using the aluminum chloride

191 colorimetric method (Chatatikun et al., 2020). Briefly, $100 \mu \mathrm{L}$ CFS of Lactobacillus or quercetin

$192(1.56-100 \mu \mathrm{g} / \mathrm{mL})$ was incubated with $100 \mu \mathrm{L}$ of $2 \% \mathrm{AlCl}_{3}$ solution in methanol for $30 \mathrm{~min}$ at

193 room temperature, and the absorbance was measured at $415 \mathrm{~nm}$. The TFC was calculated from a

194 calibration curve, and the result was expressed as mg quercetin equivalents (QE) per g of

195 lyophilized CFS of Lactobacillus.

196 2.7.3 2,2-Diphennyl-1-picrylhydrazyl (DPPH) radical scavenging activity

197 The free-radical-scavenging activities of LCFS of Lactobacillus were measured using the DPPH

198 assay with Trolox (Sigma-Aldrich, St. Louis, USA) as the standard. This assay was performed

199 according to the procedure previously described by Chatatikun et al. (Chatatikun et al., 2020)

200 with some modifications. Briefly, $1000 \mu \mathrm{g} / \mathrm{ml}$ of CFS of Lactobacillus $(20 \mu \mathrm{L})$ or 1.56 to

$201100 \mu \mathrm{g} / \mathrm{ml}$ ascorbic acid standard in absolute ethanol was added to $180 \mu \mathrm{L}$ of DPPH working

202 solution. Then, the mixture was shaken and incubated in the dark for $30 \mathrm{~min}$. The absorbance

203 was read at $517 \mathrm{~nm}$ against a blank. The assays were done in triplicate. The DPPH scavenging

204 activity was calculated using the following equation:

$205 \%$ Scavenging activity $=100 \times$ (Abs of control $-($ Abs of sample - Abs of blank) $) /$ Abs of control.

206 IC50, the concentration resulting in 50\% inhibition of DPPH, was determined from a graph of

207 free-radical-scavenging activity.

208

$2092.8 \mathrm{ABTS}^{+}$radical scavenging activity

210 ABTS $^{*}+$ is generated by oxidation with a strong oxidizing agent (potassium persulfate). The

211 reduction of a blue-green color of ABTS*+ free radical by donating hydrogen antioxidants from

212 LCFS is determined by the decrease of its absorbance. The ABTS ${ }^{+}$radical scavenging activity of

213 LCFS of Lactobacillus was evaluated using an ABTS decolorization assay as published by

214 Chatatikun et al. (Chatatikun et al., 2020) with modifications. Briefly, $\mathrm{ABTS}^{+}$was produced by

215 mixing $7 \mathrm{mM}$ ABTS and $2.45 \mathrm{mM}$ potassium sulfate at a ratio of $2: 3(\mathrm{v} / \mathrm{v})$. The $\mathrm{ABTS}^{+}$was

216 stored in the dark at room temperature for $15 \mathrm{~h}$ until it was used. The $\mathrm{ABTS}^{+}$solution was

PeerJ reviewing PDF | (2021:09:65883:1:1:NEW 20 Oct 2021) 
217 diluted with methanol to reach an absorbance of $0.70 \pm 0.02$. Then, $20 \mu \mathrm{L}$ of CFS of

218 Lactobacillus were mixed with $180 \mu \mathrm{L}$ of $\mathrm{ABTS}^{+}$solution and incubated for $45 \mathrm{~min}$. The assays

219 were done in triplicate. The percent inhibition of absorbance at $734 \mathrm{~nm}$ was calculated using the

220 following equation:

$221 \%$ Scavenging activity $=100 \times$ (Abs of control - (Abs of sample - Abs of blank) $) /$ Abs of control.

222 IC50 was determined as the concentration resulting in 50\% inhibition of $\mathrm{ABTS}^{+}$

223

224

2.9. Determination of anti-inflammatory activity

225 2.9.1. Cell culture

226 RAW 264.7 cells, a mouse macrophage cells were kindly provided by Assoc. Prof. Dr.

227 Potchanapond Graidist, Department of Biomedical Sciences and Biomedical Engineering,

228 Faculty of Medicine, Prince of Songkla University, Hatyai, Songkhla, Thailand. RAW 264.7

229 cells were cultured in Dulbecco's Modified Eagle's Medium (DMEM; Gibco, Thermo Fisher

230 Scientific, NY, USA) with 10\% fetal bovine serum (Gibco) and 1\% penicillin- streptomycin

231 solution (Gibco, Thermo Fisher Scientific) at $37^{\circ} \mathrm{C}$ in $5 \% \mathrm{CO}_{2}$. The RAW 264.7 cells were

232 subcultured and plated at $80 \%-90 \%$ confluency.

233 2.9.2. Cell viability assays

234 MTT assays were performed to assess the effect of LCFS of Lactobacillus on the viability of

235 RAW 264.7 cells with modifications (Khanna, Bishnoi, Kondepudi, \& Shukla, 2020). Briefly,

236 RAW 264.7 cells were seeded onto 96-well microplates at $1 \times 10^{5}$ cells $/ \mathrm{mL}$ and incubated at

$23737^{\circ} \mathrm{C}$ in a $5 \% \mathrm{CO}_{2}$ incubator for cytotoxicity assays. The cells were then treated with CFS from

238 Lactobacillus and incubated at $37^{\circ} \mathrm{C}$ for $16 \mathrm{~h}$. After incubation, supernatants were discarded and

239 the cells were washed with PBS. A volume of $50 \mu \mathrm{L}$ of 3-(4,5-dimethylthiazol-2-yl)-2,5-

240 diphenyl tetrazolium bromide (MTT) solution (Sigma, MO, USA) $(0.5 \mathrm{mg} / \mathrm{mL}$ in DMEM) was

241 added to each well and incubated for $4 \mathrm{~h}$ in the dark after removing the treatment mixture from

242 each well. The formazan crystals were dissolved by adding $100 \mu \mathrm{L}$ of dimethylsulfoxide

243 (DMSO) solution (Sigma, MO, USA). The OD was measured at $570 \mathrm{~nm}$ using a microplate

244 reader. The experiment was repeated three times with triplicate samples. The percentage of cell

245 viability was calculated using the following equation:

$246 \%$ cell viability $=(\mathrm{OD}$ of test $/ \mathrm{OD}$ of untreated control $) \times 100$

247 2.9.3. Nitric oxide assays

PeerJ reviewing PDF | (2021:09:65883:1:1:NEW 20 Oct 2021) 
248 To evaluate their anti-inflammatory activity, the LCFS of Lactobacillus were tested for their 249 ability to reduce lipopolysaccharide (LPS)-induced nitric oxide (NO) generation in RAW 264.7 250 cells according to the method of Khanna et al. (Khanna et al., 2020) with slight modifications. 251 Briefly, RAW 264.7 cells were seeded in a 24-well microplate and treated with $96.52 \mu \mathrm{g} / \mathrm{L}$ of 252 LCFS of Lactobacillus with or without $1 \mu \mathrm{g} / \mathrm{ml}$ of LPS (Sigma-Aldrich, St. Louis, USA). RAW 253264.7 cells treated with $1 \mu \mathrm{g} / \mathrm{ml}$ of LPS alone were used as the positive control. After $24 \mathrm{~h}$ of 254 incubation at $37^{\circ} \mathrm{C}$ in $5 \% \mathrm{CO}_{2}$, the nitric oxide production was measure by treating the 255 supernatant with an equal volume of Griess reagent (Sigma-Aldrich, St. Louis, USA). The OD 256 was measured at $570 \mathrm{~nm}$ using a microplate reader. Each test was performed in triplicate. The 257 concentration of nitric oxide production was calculated using the following equation:

258 Nitric oxide production $=(\mathrm{OD}$ of test $/ \mathrm{OD}$ of standard $) \times$ concentration of standard 259

260

\subsection{Statistical analysis}

262

Data are expressed as mean \pm standard error calculated over three independent experiments 263 performed in triplicate. Statistical significance was calculated using One-way ANOVA followed by Tukey's post-hoc test. $p<0.05$ was considered as significant. GraphPad Prism version 9 264 software was used for all analysis.

265

266

267

\section{Results}

268

269

270

271

272

273 274

275

276

277 278

\subsection{Determination of MIC and $M B C$}

The antibacterial activities of the LCFS of Lactobacillus against the four pathogenic bacteria were determined using a broth microdilution assay. As shown in Table 1, the 10 LCFS of Lactobacillus showed strong antibacterial activity and inhibited E. coli DMST4212, A.

baumannii DMST 2271, S. aureus DMST 2928, and MRSA with MIC values in the range of 25$50 \mathrm{mg} / \mathrm{mL}$. The MBC values of these LCFS of Lactobacillus were $>100 \mathrm{mg} / \mathrm{mL}$. The LCFS of Lactobacillus T0902, T1301, and T1304 did not inhibit S. aureus DMST 2928 or MRSA.

\subsection{Reduction of biofilm formation in A. baumannii and E. coli by LCFS of Lactobacillus}

The inhibitory activities of the LCFS of Lactobacillus against biofilm formation by A. baumannii and E. coli were determined using the crystal violet assay. As shown in Figure 1 and Table S1, the concentration of the CFS tested significantly inhibited biofilm formation by E. coli when 
279 compared with the control. At $2 \times$ MIC, the CFS produced by the isolates T0601 and T0802 280 exhibited the highest inhibition (mean \pm standard deviation) of $43.86 \% \pm 1.15 \%$ and $41.35 \% \pm$ 281 $4.19 \%$, respectively, against $E$. coli biofilm (Table S1). It has been highlighted that at $2 \times$ MIC of

282 the supernatant of the probiotics T0701 and T1304 significantly inhibited E. coli biofilm 283 formation, compared with the concentration at $1 \times$ MIC. The isolate T0802 also exhibited the 284 highest inhibition of $29.33 \% \pm 1.15 \%$ against $A$. baumannii biofilm. A significant difference in 285 inhibition was observed when the bacteria were treated with $2 \times$ MIC of CFS produced by the 286 isolate T0802 when compared with $1 \times$ MIC of the CFS. It has noticed that antibiofilm activity 287 of the supernatant of the probiotics against both $S$. aureus and MRSA was performed. However, 288 the results demonstrated that the supernatant did not inhibit the biofilms of both the strains. 289 290 291 292 293 294 295 296

300

301

302 303 304 305 306 307

3.3 Activity of LCFS on the eradication of the established biofilms of A. buamannii and E. coli The activity of the LCFS of Lactobacillus on the established biofilms of A. baumannii and $E$. coli was assessed using the crystal violet assay. As shown in Figure 2 and Table S2, a significant decrease in the viability of mature two-day-old biofilm-grown cells of both A. baumannii and $E$. coli was observed after treatment with the LCFS of Lactobacillus at $2 \times \mathrm{MIC}$ and $1 \times \mathrm{MIC}$ when compared with the negative control $(P<0.05)$. The CFS from the isolate T1901 resulted in the highest eradication of $62.98 \% \pm 3.54 \%$ and $84.34 \% \pm 0.98 \%$ of the established biofilm of $A$. baumannii and E. coli, respectively. A significant difference in the eradication was observed when the bacterial cells were treated with $2 \times$ MIC of CFS produced by the isolate T1901 when compared with $1 \times$ MIC of the CFS.

\subsection{Antioxidant activity of LCFS from Lactobacillus}

The antioxidant activities of all isolates were evaluated by measuring the TPC, TFC, DPPH radical scavenging activity, and $\mathrm{ABTS}^{+}$radical scavenging activity (Figures 3 and 4). The TPC value of the LCFS of Lactobacillus ranged from $202.7 \pm 1.42 \mu \mathrm{g} \mathrm{GAE} / \mathrm{g}$ to $283.4 \pm 11.91 \mu \mathrm{g} \mathrm{GAE} / \mathrm{g}$ (Figure 3A). LCFS of $L$. paracasei T0901 showed the highest TPC value $(283.4 \pm 11.91 \mu \mathrm{g} \mathrm{GAE} / \mathrm{g})$, followed by LCFS of $L$. paracasei $\mathrm{T} 0902(274.7 \pm 8.34 \mu \mathrm{g} \mathrm{GAE} / \mathrm{g})$ and LCFS of $L$. paracasei $\mathrm{T} 1302(260.3 \pm 8.69 \mu \mathrm{g} \mathrm{GAE} / \mathrm{g})$.

Values of TFC were determined in $\mathrm{mg}$ QE/g of lyophilized CFS of Lactobacillus. The $\mathrm{TFC}$ value of the LCFS ranged from $22.26 \pm 0.94 \mu \mathrm{g} \mathrm{QE} / \mathrm{g}$ to $56.60 \pm 1.34 \mu \mathrm{g} \mathrm{QE} / \mathrm{g}$ (Figure 3B). 
310 LCFS of L. paracasei T1304 showed the highest TFC value (56.60 $\pm 1.34 \mu \mathrm{g}$ QE/g), followed by 311 LCFS of L. paracasei T0601 (56.03 $\pm 1.23 \mu \mathrm{g}$ QE/g) and LCFS of L. paracasei T0902 (50.19 \pm $3122.15 \mu \mathrm{g} \mathrm{QE} / \mathrm{g})$.

313 The DPPH radical and $\mathrm{ABTS}^{+}$radical scavenging activities were used as a tool to investigate the 314 antioxidant properties of the 10 LCFS Lactobacillus isolates (Figure 4A). The results showed 315 that all the isolates had antioxidant property.

316 The LCFSs of L. paracasei T0902 exhibited strong DPPH radical scavenging activities (117.2 \pm $3170.26 \mu \mathrm{g} \mathrm{VCEAC} / \mathrm{mL})$, followed by LCFS of L. paracasei T1301 (116.8 $\pm 0.53 \mu \mathrm{g} \mathrm{VCEAC} / \mathrm{mL})$ 318 and LCFS of L. paracasei T1304 (115.9 $\pm 0.47 \mu \mathrm{g} \mathrm{VCEAC/mL).} \mathrm{This} \mathrm{difference} \mathrm{was} \mathrm{not}$ 319 statistically significant ( $\mathrm{p}>0.05)$. The antioxidant activity (ABTS) of all LCFS of L. paracasei 320 isolates ranged from $16.46 \pm 0.67 \mu \mathrm{g} \mathrm{VCEAC} / \mathrm{mL}$ to $38.1 \pm 1.37 \mu \mathrm{g} \mathrm{VCEAC} / \mathrm{mL}$. All of these 321 LCFS were significantly different from each other. The LCFS of L. paracasei T0902 displayed 322 the highest $\mathrm{ABTS}^{+}$radical scavenging activity $(38.1 \pm 1.37 \mu \mathrm{g} \mathrm{VCEAC} / \mathrm{mL})$, followed by LCFS 323 of L. fermentum T0701 (37.51 $\pm 2.25 \mu \mathrm{g}$ VCEAC/mL) and LCFS of L. brevis T0802 (37.32 \pm 324 $0.34 \mu \mathrm{g}$ VCEAC/mL), which were not significantly different from LCFS of L. paracasei T0902.

325

326

\subsection{Cell viability by MTT assay}

327

We evaluated the cytotoxicity of the 10 LCFS of Lactobacillus isolates in RAW 264.7 cells

328 using MTT assays. None of these isolates produced any significant cytotoxicity in the concentration range of 5.00-118.80 mg/mL (Figure S1). Thus, the LCFS was considered to be safe and was evaluated further.

331

332

\subsection{NO production}

333 NO is a multifunctional mediator and plays a pivotal role in the immune response to inflammation. Results of the NO assay (Figure 5) established that the LCFS of Lactobacillus showed a wide range of NO production levels. All of these isolates reduced the NO production to $<10 \mu \mathrm{M}(4.17 \pm 1.61-8.66 \pm 0.23 \mu \mathrm{M})$ in LPS-stimulated RAW 264.7 cells when compared with untreated LPS-stimulated RAW 264.7 cells $(39.89 \pm 0.91 \mu \mathrm{M})$. Among the isolates, LCFS of $L$. paracasei T0601 exhibited the lowest NO production $(4.17 \pm 1.61 \mu \mathrm{M})$ in LPS-stimulated RAW 264.7 cells, followed by LCFS of $L$. paracasei T0602 $(5.17 \pm 0.05 \mu \mathrm{M})$ and LCFS of L. brevis 
341 was $10.06 \pm 0.50 \mu \mathrm{M}$ and was not significantly different from that of the LCFS of Lactobacillus

342 treated LPS-stimulated RAW 264.7 cells.

343

\section{Discussion}

345 Probiotics are living microorganisms that confer health benefits to the host when administered in

346 adequate amounts. Moreover, dead bacteria, inactivated bacteria, and bacterial components can

347 also display probiotic properties (Plaza-Diaz et al., 2019). Probiotics are safe, survive in the

348 gastrointestinal tract, produce active molecules that inhibit pathogens, stimulate the immune

349 system, and aid in the improvement of intestinal barrier function and microflora (De Marco et al.,

350 2018; Plaza-Diaz et al., 2019). In our previous report (Sornsenee et al., 2021), 10 lactobacilli

351 isolated from fermented palm sap serve as promising candidates for probiotics since they exhibit

352 potential probiotic properties. Probiotic microorganisms, especially Lactobacillus species, are

353 used as dietary supplements and capsules and in probiotic foods, beverages, and probiotic juices

354 (Saxelin, Tynkkynen, Mattila-Sandholm, \& de Vos, 2005). Commercial Lactobacillus strains

355 include L. acidophilus NCFM, L. acidophilus La-5, L. casei Shirota, L. casei DN-114 001, L.

356 reuteri DSM 17938, L. rhamnosus GG, L. rhamnosus HN001, L. rhamnosus GR-1, L. paracasei

357 F19, and L. plantarum 299v (Delley et al., 2015; Tremblay, Xu, Colee, \& Tompkins, 2021).

358 Some Lactobacillus spp. are GRAS by the European Food Safety Authority (EFSA) and FDA

359 (Ogier \& Serror, 2008; Plaza-Diaz et al., 2019). The effects of these probiotics on host health

360 have been reported in many studies (Barzegari et al., 2020; Chatatikun et al., 2020; Hotel \&

361 Cordoba, 2001; Saxelin et al., 2005; Stefania et al., 2017). Dead bacteria, metabolic by-products,

362 and bacterial molecular components have also been shown to exhibit probiotic effects in various

363 studies (De Marco et al., 2018; Yang et al., 2021). Currently, the term "postbiotic" refers to

364 soluble components with biological activity that could be a safer alternative to the use of whole

365 bacteria (Tsilingiri et al., 2012).

366 Antimicrobial susceptibility tests showed that all LCFS of Lactobacillus isolates had

367 strong inhibitory effects on the four tested pathogens: E. coli DMST4212, A. baumannii DMST

368 2271, S. aureus DMST 2928, and MRSA. According to the results of MIC and MBC assays, the

$369 \mathrm{MBC} / \mathrm{MIC}$ ratio was more than four times that considered to be valuable as a bacteriostatic agent

370 (Levison, 2004). Thus, these LCFS of Lactobacillus isolates are potential antibacterial agents.

371 Our results agree with those of previous studies; for example, Melo et al. (Melo et al., 2016) 
372 reported that Lactobacillus supernatants inhibited S. aureus. Other reports have shown that the

373 lyophilized cell-free extract of L. casei can inhibit E. coli, Salmonella typhi, Pseudomonas

374 aeruginosa, S. aureus, and MRSA (Saadatzadeh, Fazeli, Jamalifar, \& Dinarvand, 2013).

375 Lactobacilli can produce various secondary metabolites that exhibit antimicrobial activity, such

376 as organic acids, ethyl alcohol, short-chain fatty acids, bacteriocins, hydrogen peroxide,

377 surfactants, and bacteriocins (Melo et al., 2016; Plaza-Diaz et al., 2019).

378 Biofilm-related infections are a serious clinical problem and include chronic infections. Since

379 biofilms are not fully available to the human immune system or antibiotics, they are difficult to 380 eradicate and control, which leads to the emergence of antibiotic-resistant strains (Barzegari et

381 al., 2020; Khairy, Fathy, Mahrous, Mohamed, \& Abdelrahim, 2020). The present study revealed

382 that all LCFS of Lactobacillus isolates were able to not only inhibit pathogen biofilm formation

383 but also eradicate mature biofilms of E. coli DMST4212 and A. baumannii DMST 2271.

384 Probiotics can interrupt the activity of pathogens and their adhesion to surfaces. Probiotics

385 prevent quorum sensing and biofilm formation, interfere with biofilm integrity, and eradicate 386 biofilms by secreting antagonistic substances (Plaza-Diaz et al., 2019). These data, according to 387 Kim et al. (Kim, Kim, \& Kang, 2019), showed that L. brevis DF01 bacteriocin can inhibit the

388 formation of biofilms by E. coli and S. typhimurium. Other study from Rossoni et al. reported 389 that L. fermentum 20.4, L. paracasei 11.6, L. paracasei 20.3, and L. paracasei 25.4 produce 390 bioactive substances that caused a significant reduction in S. mutans biofilms (Rossoni et al., 391 2018). Furthermore, the result similar to report from Carvalho et al., (Carvalho et al., 2021), L. 392 plantarum showed promising results against pathogenic biofilms. Some of the bacteriocins 393 eradicate biofilms by inducing the formation of pores on the bacterial cell surface, which leads to 394 ATP efflux, while others exert their biological activity through proteolytic enzymes (Okuda et 395 al., 2013). We consider all LCFS of Lactobacillus isolates to be potentially applicable for 396 reducing the formation of biofilms and for eradicating the established biofilms of E. coli and $A$.

397 baumannii.

398 The isolates have desirable properties as potential probiotics. During fermentation, lactobacilli 399 can produce phenolic and flavonoid compounds as end products. The increase in the production 400 of these compounds during the enzymatic hydrolysis of lactobacilli during fermentation leads to 401 an increase in their antioxidant activities (Filannino, Bai, Di Cagno, Gobbetti, \& Gänzle, 2015).

402 In this study, we investigated the total phenolic and flavonoid contents of the LCFS of 
403 Lactobacillus isolates. All isolates contained high levels of these compounds. These findings 404 agree with those of Talib et al. (Talib et al., 2019) who reported that Lactobacillus spp. showed 405 high antioxidant activities for TPC and TFC. Another study found that $L$. plantarum can produce 406 high levels of phenolic compounds during fermentation (Xiao et al., 2015). The LCFS of 407 Lactobacillus isolates exhibited strong DPPH and ABT + radical scavenging activities. Several 408 probiotics can enhance the activity of antioxidant enzymes or modulate circulatory oxidative 409 stress (Mishra et al., 2015). The CFS of L. acidophilus, L. casei, Lactococcus lactis, L. reuteri, and Saccharomyces boulardii could reduce oxidative damage and free-radical-scavenging rate 412 showed varying capabilities of DPPH radical scavenging. Thus, these results suggest that 413 phenolics and flavonoids are the major compounds responsible for the antioxidant activities. 414 Inflammation is the mark of many inflammatory disorders such as chronic peptic ulcer, Crohn's 415 disease, and infections. The intestinal immune system has developed distinct mechanisms to 416 dampen mucosal immunity and to optimize the response against microbiota. NO is a 417 multifunctional mediator and plays an essential role in the immune response to inflammatory 418 activity. Normal NO production in the phagocytes is beneficial for host defense against 419 pathogens and cancer cells (Abdulkhaleq et al., 2018). Proinflammatory cytokines are commonly 420 induced by the LPS cell-wall component of gram-negative bacteria. In this study, the LCFS of 421 Lactobacillus isolates showed low levels of NO production. The supernatant did not exhibit any 422 cytotoxic activity against the RAW 264.7 cells. Recently, there have been a few studies on the 423 anti-inflammatory activity of the CFS of probiotics. Kang et al. (Kang, Kim, Park, Kim, \& Paek, 424 2021) observed that Bifidobacterium bifidum MG731, B. lactis MG741, and L. salivarius 425 MG242 showed low NO production. In another report, the CFS of L. acidophilus and $L$. 426 rhamnosus $G G$ showed anti-inflammatory properties and modulated the inflammatory response 427 (Maghsood et al., 2018). Thus, reduced NO production by the LCFS of Lactobacillus isolates 428 may be due to the downregulation of inducible NO synthase, the main mediator of various 429 chronic inflammatory diseases (Oh et al., 2012).

430 Exploiting the LCFS of Lactobacillus isolates in the preparation of probiotic products is an 431 innovative approach and has the potential to replace the living probiotic cells.

\section{Conclusions}


434 The present study revealed that the 10 LCFS of Lactobacillus isolates exhibited antibacterial 435 activity, reduced the formation of biofilms, and eradicated the established biofilm. These 436 supernatants contain phenolic and flavonoid compounds and display antioxidant and anti437 inflammatory activities in RAW 264.7 cells. Therefore, they are promising novel postbiotic 438 candidates for use in functional foods and pharmaceuticals. Further research to elucidate the 439 precise molecular mechanisms of action of probiotics is warranted.

440

\section{Acknowledgements}

442 The authors thank the Research Institute for Health Sciences Walailak University, School of 443 Allied Health Sciences, Walailak University, for providing the required laboratory instruments. 444

\section{References}

446

(CLSI), C. a. L. S. I. (2021). Performance Standards for Antimicrobial Susceptibility Testing

447

448

449

450

451

452

453

454

455

456

457

458

459

460

461

462

463

464 CLSI supplement M100. CLSI (31st ed.). 950 West Valley Road, Suite 2500, Wayne, Pennsylvania 19087 USA.

Abdulkhaleq, L. A., Assi, M. A., Abdullah, R., Zamri-Saad, M., Taufiq-Yap, Y. H., \& Hezmee, M. N. M. (2018). The crucial roles of inflammatory mediators in inflammation: A review. Veterinary world, 11(5), 627-635. doi:10.14202/vetworld.2018.627-635

AlKalbani, N. S., Turner, M. S., \& Ayyash, M. M. (2019). Isolation, identification, and potential probiotic characterization of isolated lactic acid bacteria and in vitro investigation of the cytotoxicity, antioxidant, and antidiabetic activities in fermented sausage. Microb Cell Fact, 18(1), 188. doi:10.1186/s12934-019-1239-1

Barzegari, A., Kheyrolahzadeh, K., Hosseiniyan Khatibi, S. M., Sharifi, S., Memar, M. Y., \& Zununi Vahed, S. (2020). The Battle of Probiotics and Their Derivatives Against Biofilms. Infection and drug resistance, 13, 659-672. doi:10.2147/IDR.S232982

Behera, S. S., Ray, R. C., \& Zdolec, N. (2018). Lactobacillus plantarum with functional properties: an approach to increase safety and shelf-life offermented foods. Biomed Res. Int, 2018, 9361614-9361614. doi:10.1155/2018/9361614

Bermudez-Brito, M., Plaza-Diaz, J., Munoz-Quezada, S., Gomez-Llorente, C., \& Gil, A. (2012). Probiotic mechanisms of action. Ann Nutr Metab, 61(2), 160-174. doi:10.1159/000342079 
465 Carvalho, F. M., Teixeira-Santos, R., Mergulhão, F. J. M., \& Gomes, L. C. (2021). Effect of

466

467

468

469

470

471

472

473

474

475

476

477

478

479

480

481

482

483

484

485

486

487

488

489

490

491

492

493

494

Lactobacillus plantarum Biofilms on the Adhesion of Escherichia coli to Urinary Tract Devices. Antibiotics, 10(8), 966. Retrieved from https://www.mdpi.com/2079$\underline{6382 / 10 / 8 / 966}$

Chatatikun, M., Supjaroen, P., Promlat, P., Chantarangkul, C., Waranuntakul, S., Nawarat, J., . . Chiabchalard, A. (2020). Antioxidant and Tyrosinase Inhibitory Properties of an Aqueous Extract of Garcinia atroviridis Griff. ex. T. Anderson Fruit Pericarps. Pharmacognosy Journal, 12, 71-79. doi:10.5530/pj.2020.12.12

Chen, C.-C., Lai, C.-C., Huang, H.-L., Huang, W.-Y., Toh, H.-S., Weng, T.-C., . . Tang, H.-J. (2019). Antimicrobial activity of Lactobacillus Species against carbapenem-resistant enterobacteriaceae. Frontiers in Microbiology, 10(789). doi:10.3389/fmicb.2019.00789

Cremon, C., Barbaro, M. R., Ventura, M., \& Barbara, G. (2018). Pre- and probiotic overview. Current Opinion in Pharmacology, 43, 87-92. doi:https://doi.org/10.1016/j.coph.2018.08.010

De Marco, S., Sichetti, M., Muradyan, D., Piccioni, M., Traina, G., Pagiotti, R., \& Pietrella, D. (2018). Probiotic Cell-Free Supernatants Exhibited Anti-Inflammatory and Antioxidant Activity on Human Gut Epithelial Cells and Macrophages Stimulated with LPS. Evidence-based complementary and alternative medicine : eCAM, 2018, 17563081756308. doi:10.1155/2018/1756308

Delley, M., Bruttin, A., Richard, M., Affolter, M., Rezzonico, E., \& Brück, W. M. (2015). In vitro activity of commercial probiotic Lactobacillus strains against uropathogenic Escherichia coli. FEMS Microbiol Lett, 362(13), fnv096. doi:10.1093/femsle/fnv096

FAO/WHO. (2002). Guidelines for the Evaluation of Probiotics in Food. Report of a Joint FAO/WHO Working Group on Drafting Guidelines for the Evaluation of Probiotics in Food.

Filannino, P., Bai, Y., Di Cagno, R., Gobbetti, M., \& Gänzle, M. G. (2015). Metabolism of phenolic compounds by Lactobacillus spp. during fermentation of cherry juice and broccoli puree. Food Microbiol, 46, 272-279. doi:10.1016/j.fm.2014.08.018

Gómez, N. C., Ramiro, J. M. P., Quecan, B. X. V., \& de Melo Franco, B. D. G. (2016). Use of Potential Probiotic Lactic Acid Bacteria (LAB) Biofilms for the Control of Listeria 
495

496

497

498

499

500

501

502

503

504

505

506

507

508

509

510

511

512

513

514

515

516

517

518

519

520

521

522

523 monocytogenes, Salmonella Typhimurium, and Escherichia coli O157:H7 Biofilms Formation. Frontiers in Microbiology, 7(863). doi:10.3389/fmicb.2016.00863

Hotel, A. C. P., \& Cordoba, A. (2001). Health and nutritional properties of probiotics in food including powder milk with live lactic acid bacteria. Prevention, 5(1), 1-10.

Hussain, A. I., Anwar, F., Nigam, P. S., Sarker, S. D., Moore, J. E., Rao, J. R., \& Mazumdar, A. (2011). Antibacterial activity of some Lamiaceae essential oils using resazurin as an indicator of cell growth. LWT - Food Science and Technology, 44(4), 1199-1206. doi:https://doi.org/10.1016/j.lwt.2010.10.005

Ji, J., \& Yang, H. (2021). In Vitro Effects of Lactobacillus plantarum LN66 and Antibiotics Used Alone or in Combination on Helicobacter pylori Mature Biofilm. Microorganisms, 9(2), 424. doi:10.3390/microorganisms9020424

Kang, C. H., Kim, J. S., Park, H. M., Kim, S., \& Paek, N. S. (2021). Antioxidant activity and short-chain fatty acid production of lactic acid bacteria isolated from Korean individuals and fermented foods. 3 Biotech, 11(5), 217. doi:10.1007/s13205-021-02767-y

Kariyawasam, K. M. G. M. M., Yang, S. J., Lee, N.-K., \& Paik, H.-D. (2020). Probiotic properties of Lactobacillus brevis KU200019 and synergistic activity with fructooligosaccharides in antagonistic activity against foodborne pathogens. Food science of animal resources, 40(2), 297-310. doi:10.5851/kosfa.2020.e15

Khairy, R. M. M., Fathy, Z. A., Mahrous, D. M., Mohamed, E. S., \& Abdelrahim, S. S. (2020). Prevalence, phylogeny, and antimicrobial resistance of Escherichia coli pathotypes isolated from children less than 5 years old with community acquired- diarrhea in Upper Egypt. BMC Infectious Diseases, 20(1), 908. doi:10.1186/s12879-020-05664-6

Khanna, S., Bishnoi, M., Kondepudi, K. K., \& Shukla, G. (2020). Isolation, characterization and anti-inflammatory mechanism of probiotics in lipopolysaccharide-stimulated RAW 264.7 macrophages. World Journal of Microbiology and Biotechnology, 36(5), 74. doi:10.1007/s11274-020-02852-z

Kim, N.-N., Kim, W. J., \& Kang, S.-S. (2019). Anti-biofilm effect of crude bacteriocin derived from Lactobacillus brevis DF01 on Escherichia coli and Salmonella Typhimurium. Food control, 98, 274-280.

Peer] reviewing PDF | (2021:09:65883:1:1:NEW 20 Oct 2021) 
524 Klaenhammer, T. R., Barrangou, R., Buck, B. L., Azcarate-Peril, M. A., \& Altermann, E. (2005).

525 Genomic features of lactic acid bacteria effecting bioprocessing and health. FEMS $526 \quad$ Microbiol Rev, 29(3), 393-409. doi:10.1016/j.femsre.2005.04.007

527 Levison, M. E. (2004). Pharmacodynamics of antimicrobial drugs. Infectious Disease Clinics, $528 \quad 18(3), 451-465$.

529 Liu, C.-F., \& Pan, T.-M. (2010). In vitro effects of lactic acid bacteria on cancer cell viability $530 \quad$ and antioxidant activity. Journal of Food and Drug Analysis, 18(2).

531 Maghsood, F., Mirshafiey, A., Farahani, M. M., Modarressi, M. H., Jafari, P., \& Motevaseli, E. 532 (2018). Dual Effects of Cell Free Supernatants from Lactobacillus acidophilus and Lactobacillus rhamnosus GG in Regulation of MMP-9 by Up-Regulating TIMP-1 and Down-Regulating CD147 in PMADifferentiated THP-1 Cells. Cell J, 19(4), 559-568. doi:10.22074/cellj.2018.4447

Melo, T. A., Dos Santos, T. F., de Almeida, M. E., Junior, L. A. G. F., Andrade, E. F., Rezende, R. P., , . Romano, C. C. (2016). Inhibition of Staphylococcus aureus biofilm by Lactobacillus isolated from fine cocoa. BMC microbiology, 16(1), 250-250. doi:10.1186/s12866-016-0871-8

Mishra, V., Shah, C., Mokashe, N., Chavan, R., Yadav, H., \& Prajapati, J. (2015). Probiotics as potential antioxidants: a systematic review. J Agric Food Chem, 63(14), 3615-3626. doi:10.1021/jf506326t

Ogier, J. C., \& Serror, P. (2008). Safety assessment of dairy microorganisms: The Enterococcus genus. International Journal of Food Microbiology, 126(3), 291-301. doi:10.1016/j.ijfoodmicro.2007.08.017

Oh, Y.-C., Cho, W.-K., Oh, J. H., Im, G. Y., Jeong, Y. H., Yang, M. C., \& Ma, J. Y. (2012). Fermentation by Lactobacillus enhances anti-inflammatory effect of Oyaksungisan on LPS-stimulated RAW 264.7 mouse macrophage cells. BMC Complementary and Alternative Medicine, 12(1), 17. doi:10.1186/1472-6882-12-17

Okuda, K.-i., Zendo, T., Sugimoto, S., Iwase, T., Tajima, A., Yamada, S., . . Mizunoe, Y. (2013). Effects of bacteriocins on methicillin-resistant Staphylococcus aureus biofilm. Antimicrobial agents and chemotherapy, 57(11), 5572-5579.

Organization, F. a. A. O. o. t. U. N. W. H. (2002). Guidelines for the Evaluation of Probiotics in Food. Retrieved from 
555

556

557

558

559

560

561

562

563

564

565

566

567

568

569

570

571

572

573

574

575

576

577

578

579

580

581

582

583

584

585

https://www.who.int/foodsafety/fs management/en/probiotic guidelines.pdf. Retrieved 18 June 2020, from World Health Organization https://www.who.int/foodsafety/fs_management/en/probiotic guidelines.pdf

Perumal, S., \& Mahmud, R. (2013). Chemical analysis, inhibition of biofilm formation and biofilm eradication potential of Euphorbia hirta L. against clinical isolates and standard strains. BMC Complementary and Alternative Medicine, 13(1), 346. doi:10.1186/14726882-13-346

Pinto, A., Barbosa, J., Albano, H., Isidro, J., \& Teixeira, P. (2020). Screening of bacteriocinogenic lactic acid bacteria and their characterization as potential probiotics. Microorganisms, 8(3). doi:10.3390/microorganisms8030393

Plaza-Diaz, J., Ruiz-Ojeda, F. J., Gil-Campos, M., \& Gil, A. (2019). Mechanisms of Action of Probiotics. Advances in nutrition (Bethesda, Md.), 10(suppl_1), S49-S66. doi:10.1093/advances/nmy063

Rossoni, R. D., Velloso, M. D. S., de Barros, P. P., de Alvarenga, J. A., Santos, J. D. D., Santos Prado, A., . . . Junqueira, J. C. (2018). Inhibitory effect of probiotic Lactobacillus supernatants from the oral cavity on Streptococcus mutans biofilms. Microb Pathog, 123, 361-367. doi:10.1016/j.micpath.2018.07.032

Saadatzadeh, A., Fazeli, M. R., Jamalifar, H., \& Dinarvand, R. (2013). Probiotic Properties of Lyophilized Cell Free Extract of Lactobacillus casei. Jundishapur journal of natural pharmaceutical products, 8(3), 131-137. doi:10.17795/jjnpp-8564

Saxelin, M., Tynkkynen, S., Mattila-Sandholm, T., \& de Vos, W. M. (2005). Probiotic and other functional microbes: from markets to mechanisms. Current Opinion in Biotechnology, 16(2), 204-211. doi:https://doi.org/10.1016/j.copbio.2005.02.003

Shaaban, M., Abd El-Rahman, O. A., Al-Qaidi, B., \& Ashour, H. M. (2020). Antimicrobial and Antibiofilm Activities of Probiotic Lactobacilli on Antibiotic-Resistant Proteus mirabilis. Microorganisms, 8(6), 960. Retrieved from https:/www.mdpi.com/2076-2607/8/6/960

Shahrokhi, M., \& Nagalli, S. (2020). Probiotics. In StatPearls. Treasure Island (FL): StatPearls Publishing

Copyright (C) 2020, StatPearls Publishing LLC.

Singhal, N., Maurya, A. K., Mohanty, S., Kumar, M., \& Virdi, J. S. (2019). Evaluation of bile salt hydrolases, cholesterol-lowering capabilities, and probiotic potential of Enterococcus 
586

587

588

589

590

591

592

593

594

595

596

597

598

599

600

601

602

603

604

605

606

607

608

609

610

611

612

613

614

615

faecium isolated from rhizosphere. Frontiers in Microbiology, 10(1567).

doi:10.3389/fmicb.2019.01567

Sornsenee, P., Singkhamanan, K., Sangkhathat, S., Saengsuwan, P., \& Romyasamit, C. (2021). Probiotic Properties of Lactobacillus Species Isolated from Fermented Palm Sap in Thailand. Probiotics and Antimicrobial Proteins, 13(4), 957-969. doi:10.1007/s12602021-09754-y

Stefania, D., Miranda, P., Diana, M., Claudia, Z., Rita, P., \& Donatella, P. (2017). Antibiofilm and antiadhesive activities of different synbiotics. Journal of Probiotics and Health, 5(3), 182-191.

Talib, N., Mohamad, N. E., Yeap, S. K., Hussin, Y., Aziz, M. N. M., Masarudin, M. J., . . . Alitheen, N. B. (2019). Isolation and Characterization of Lactobacillus spp. from Kefir Samples in Malaysia. Molecules (Basel, Switzerland), 24(14), 2606. doi:10.3390/molecules24142606

Tremblay, A., Xu, X., Colee, J., \& Tompkins, T. A. (2021). Efficacy of a Multi-Strain Probiotic Formulation in Pediatric Populations: A Comprehensive Review of Clinical Studies. Nutrients, 13(6), 1908. doi:10.3390/nu13061908

Tsilingiri, K., Barbosa, T., Penna, G., Caprioli, F., Sonzogni, A., Viale, G., \& Rescigno, M. (2012). Probiotic and postbiotic activity in health and disease: comparison on a novel polarised ex-vivo organ culture model. Gut, 61(7), 1007-1015. doi:10.1136/gutjnl-2011300971

Vinderola, G., Matar, C., Palacios, J., \& Perdigón, G. (2007). Mucosal immunomodulation by the non-bacterial fraction of milk fermented by Lactobacillus helveticus R389. Int J Food Microbiol, 115(2), 180-186. doi:10.1016/j.ijfoodmicro.2006.10.020

Xiao, Y., Wang, L., Rui, X., Li, W., Chen, X., Jiang, M., \& Dong, M. (2015). Enhancement of the antioxidant capacity of soy whey by fermentation with Lactobacillus plantarum B1-6. Journal of Functional Foods, 12, 33-44.

Xu, X., Qiao, Y., Peng, Q., Shi, B., \& Dia, V. P. (2021). Antioxidant and Immunomodulatory Properties of Partially purified Exopolysaccharide from Lactobacillus Casei Isolated from Chinese Northeast Sauerkraut. Immunol Invest, 1-18. doi:10.1080/08820139.2020.1869777 
616 Yang, K. M., Kim, J.-S., Kim, H.-S., Kim, Y.-Y., Oh, J.-K., Jung, H.-W., . . Bae, K.-H. (2021).

617 Lactobacillus reuteri AN417 cell-free culture supernatant as a novel antibacterial agent

618 targeting oral pathogenic bacteria. Scientific reports, 11(1), 1631-1631.

619 doi:10.1038/s41598-020-80921-x

620 Zheng, J., Wittouck, S., Salvetti, E., Franz, C. M. A. P., Harris, H. M. B., Mattarelli, P., . .

621 Lebeer, S. (2020). A taxonomic note on the genus Lactobacillus: Description of 23 novel

622 genera, emended description of the genus Lactobacillus Beijerinck 1901, and union of

623 Lactobacillaceae and Leuconostocaceae. International Journal of Systematic and

624 Evolutionary Microbiology, 70(4), 2782-2858.

625 doi:https://doi.org/10.1099/ijsem.0.004107

626

627

628

629

630 


\section{Table 1 (on next page)}

Minimal inhibitory concentration (MIC) and minimal bactericidal concentration (MBC) of LCFS of Lactobacillus on the four pathogens

Minimal inhibitory concentration (MIC) and minimal bactericidal concentration (MBC) of LCFS of Lactobacillus on the four pathogens 
1 Table 1. Minimal inhibitory concentration (MIC) and minimal bactericidal concentration (MBC) of LCFS of

2 Lactobacillus on the four pathogens (S. aureus, MRSA, E. coli, A. baumannii)

\begin{tabular}{ccccccccc}
\hline \multirow{2}{*}{ Isolates } & \multicolumn{7}{c}{ Antimicrobial activity $(\mathrm{mg} / \mathrm{mL}$.) } \\
\cline { 2 - 9 } & \multicolumn{2}{c}{ S. aureus } & \multicolumn{2}{c}{ MRSA } & \multicolumn{2}{c}{ E. coli } & \multicolumn{2}{c}{ A. baumannii } \\
\cline { 2 - 9 } T0601 & MIC & MBC & MIC & MBC & MIC & MBC & MIC & MBC \\
\hline T0602 & 25 & $>100$ & 50 & $>100$ & 25 & $>100$ & 25 & $>100$ \\
\hline T0603 & 25 & $>100$ & 25 & $>100$ & 25 & $>100$ & 25 & $>100$ \\
\hline T0701 & 25 & $>100$ & 50 & $>100$ & 50 & $>100$ & 25 & $>100$ \\
\hline T0802 & 25 & $>100$ & 25 & $>100$ & 50 & $>100$ & 50 & $>100$ \\
\hline T0901 & 25 & $>100$ & 25 & $>100$ & 25 & $>100$ & 25 & $>100$ \\
\hline T0902 & ND & ND & ND & ND & 25 & $>100$ & 25 & $>100$ \\
\hline T1301 & ND & ND & ND & ND & 25 & $>100$ & 25 & $>100$ \\
\hline T1304 & ND & ND & ND & ND & 25 & $>100$ & 25 & $>100$ \\
\hline T1901 & 25 & $>100$ & 25 & $>100$ & 50 & $>100$ & 25 & $>100$
\end{tabular}

3 This test was performed in triplicate. ND; Not detectable, MRSA; Methicillin-resistant S. aureus

4

5 


\section{Figure 1}

Effects of the lyophilized cell-free supernatants of Lactobacillus on the inhibition of biofilm formation by $A$. baumannii and $E$. coli

Effects of the lyophilized cell-free supernatants of Lactobacillus on the inhibition of biofilm formation by A. baumannii (A) and E. coli (B). The pathogens were grown in a medium supplemented with the cell-free supernatants (CFCs) at different concentrations. CFS-free medium was used as the negative control. The relative percentage of biofilm inhibition was defined as follows: [100- (mean A570 of treated well/mean A570 of control well) $\times 100]$. The percent inhibition of each datum was compared with its negative control. The data are presented as mean \pm standard deviation (* significant difference; $P<0.05$ ). 

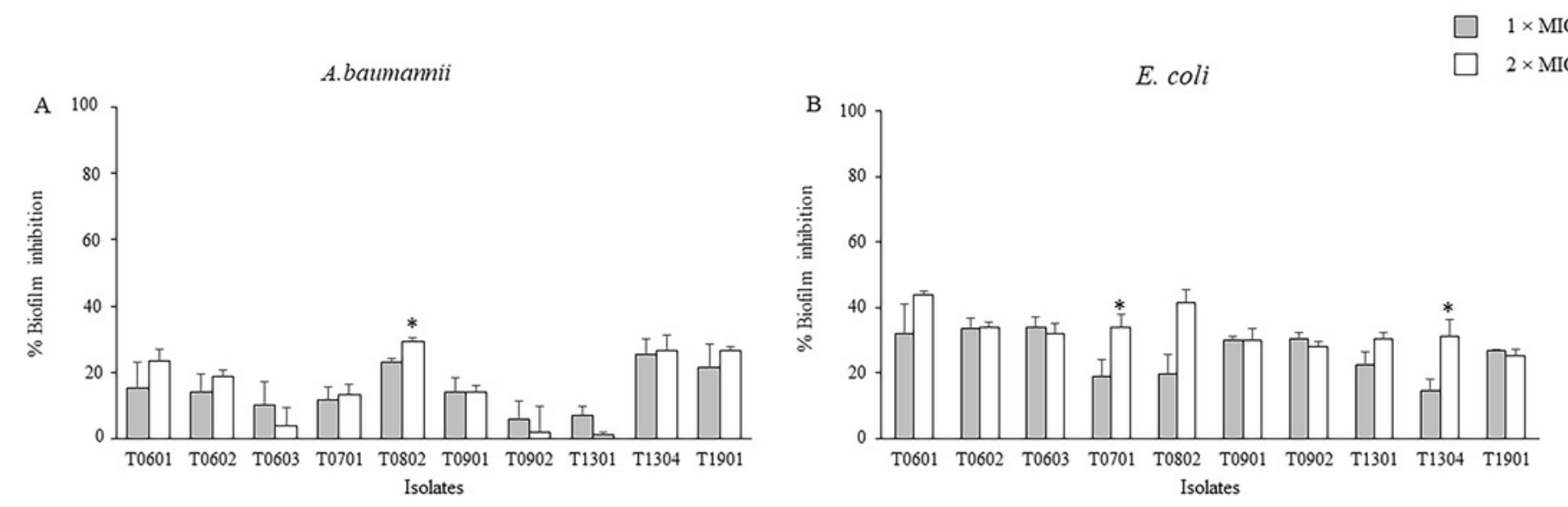


\section{Figure 2}

Effects of the lyophilized cell-free supernatants (LCFS) of Lactobacillus on the inhibition of the established biofilms of $A$. baumannii and E. coli.

Effects of the lyophilized cell-free supernatants (LCFS) of Lactobacillus on the inhibition of the established biofilms of $A$. baumannii (A) and $E$. coli (B). The bacteria were grown in a medium supplemented with glucose to produce established biofilms. The established biofilms were treated with LCFS of Lactobacillus at different concentrations. Cell-free supernatant-free medium was used as the negative control. The relative percentage of biofilm eradication was defined as follows: [100- (mean A570 of treated well/mean A570 of control well) $\times 100]$. The percent inhibition of each datum was compared with its negative control. The data are presented as mean \pm standard deviation (* significant difference; $P<0.05$ ). 

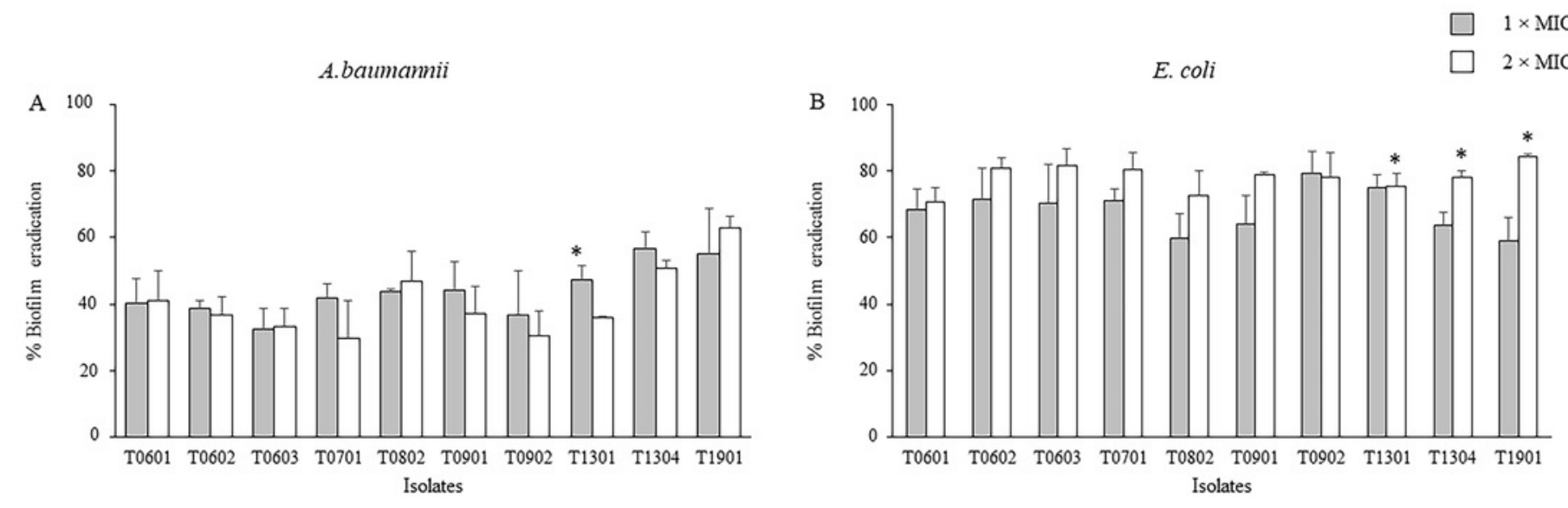
Figure 3

Total phenolic content and total flavonoid content of lyophilized cell-free supernatant of Lactobacillus.

Total phenolic content and total flavonoid content of lyophilized cell-free supernatant of Lactobacillus.
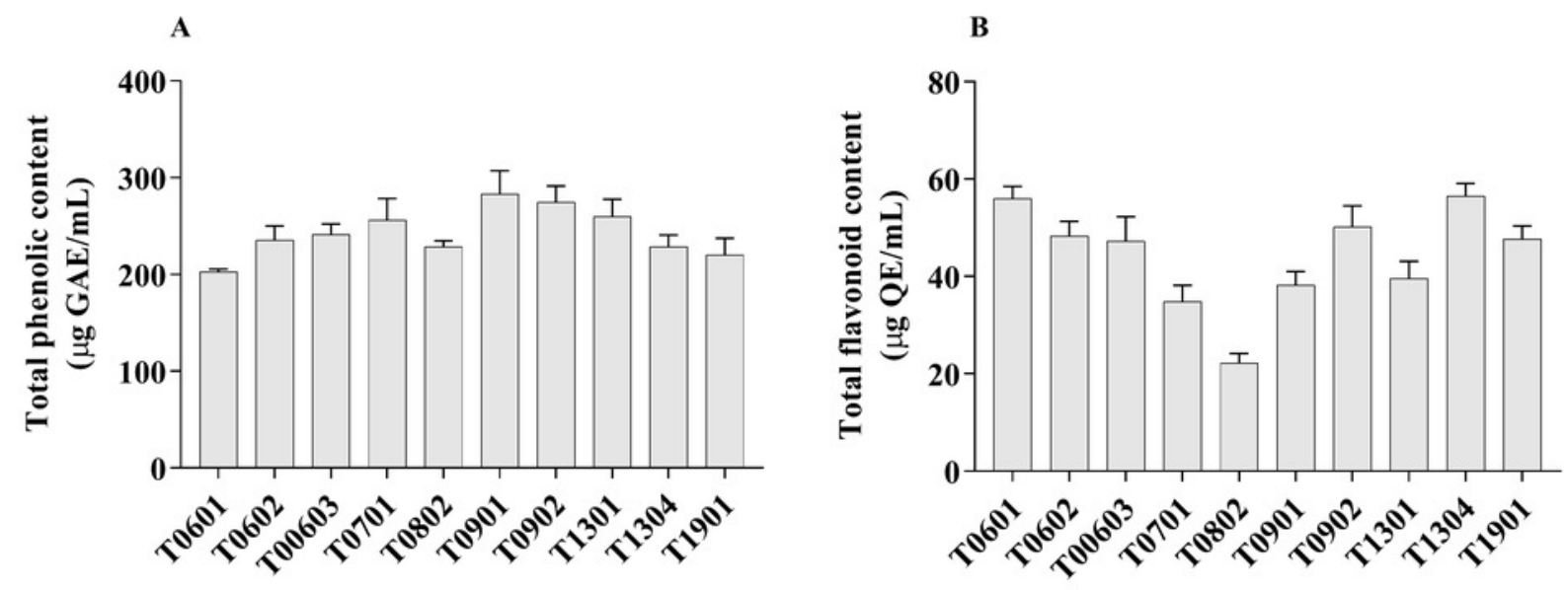
Figure 4

Scavenging activity of lyophilized cell-free supernatant (LCFS) of Lactobacillus isolates, as determined by DPPH assay and ABTS assay

Scavenging activity of lyophilized cell-free supernatant (LCFS) of Lactobacillus isolates, as determined by DPPH assay (A); ABTS radical scavenging activity of LCFS of Lactobacillus isolates (B). Values are mean \pm standard error of the mean of three replicates.
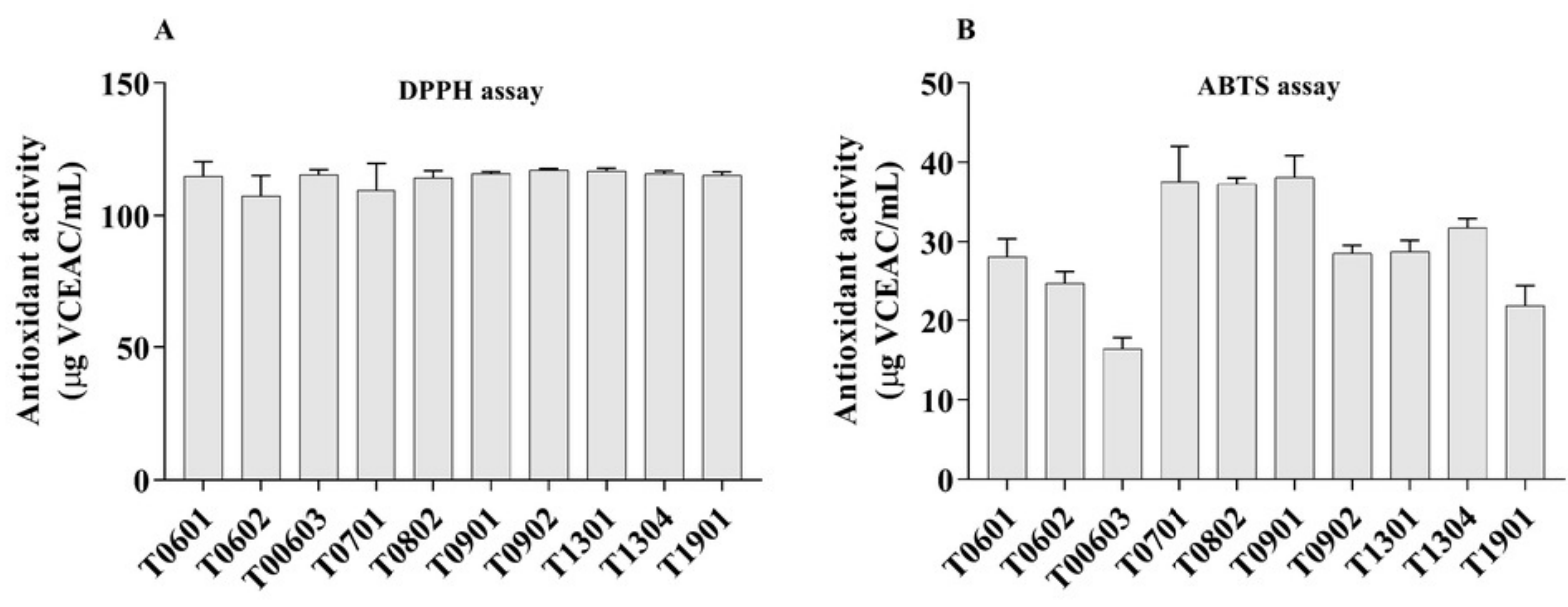


\section{Figure 5}

Inhibition of nitric oxide production in the lipopolysaccharide-stimulated RAW264.7 cells treated with the 10 lyophilized cell-free supernatants of Lactobacillus isolates

Inhibition of nitric oxide production in the lipopolysaccharide-stimulated RAW264.7 cells treated with the 10 lyophilized cell-free supernatants of Lactobacillus isolates and aspirin as control. The results are presented as the mean \pm standard deviation of three independent experiments $(n=3) . *$ and \# letters shown in the column indicate significant differences ( $p$ $<0.05)$ when compare with control, and control stimulated-LPS, respectivly.

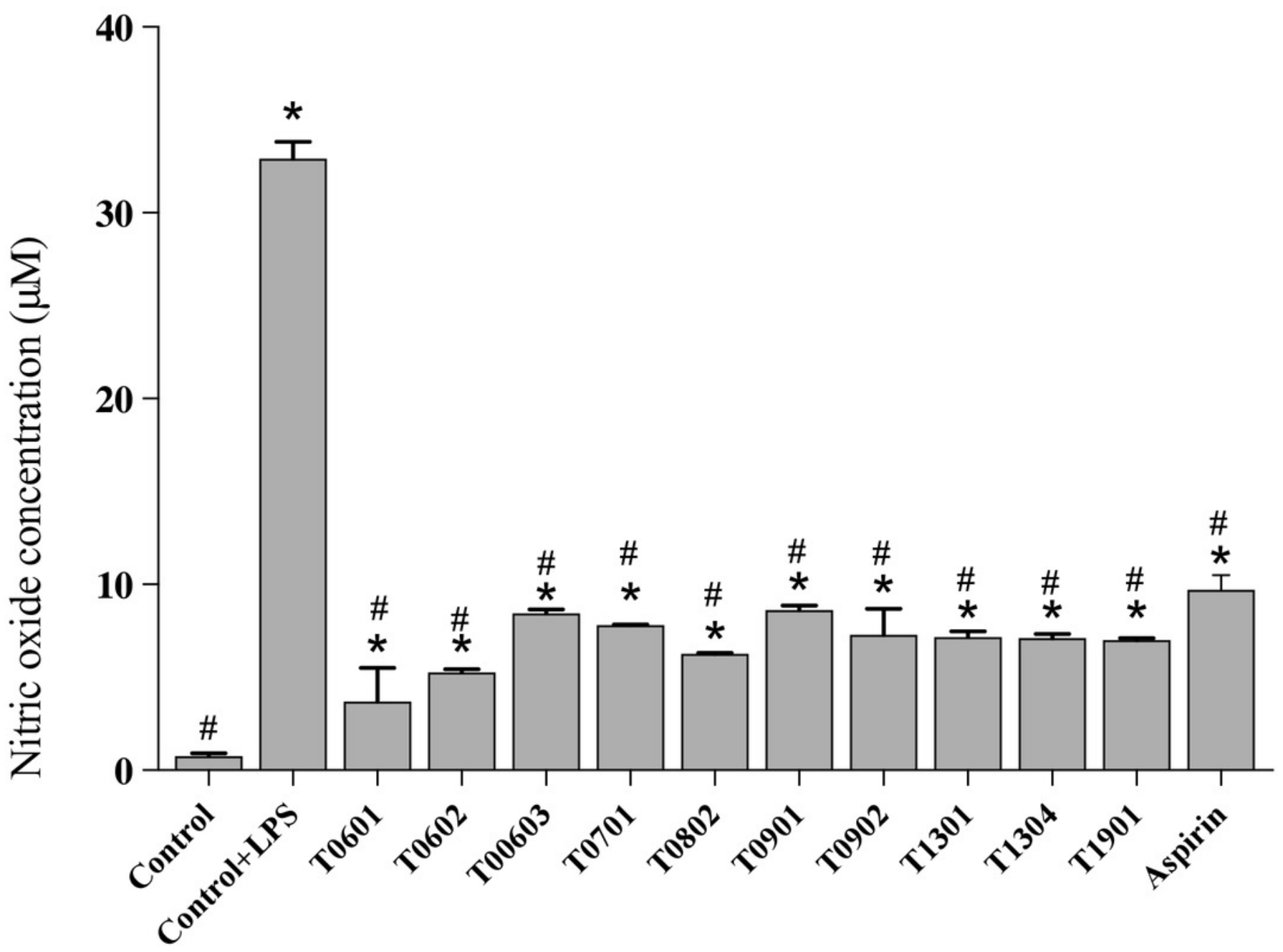

